Brit. J. industr. Med., 1962, 19, 253.

\title{
PULMONARY FIBROSIS AND ENCEPHALOPATHY ASSOCIATED WITH THE INHALATION OF ALUMINIUM DUST
}

\author{
BY \\ A. I. G. McLAUGHLIN, G. KAZANTZIS, E. KING, DONALD TEARE, \\ R. J. PORTER, and R. OWEN \\ From the Department for Research in Industrial Medicine (M.R.C.), London Hospital, \\ the Department of Forensic Medicine, St. George's Hospital, the Central Middlesex Hospital, \\ and $\boldsymbol{H}$. M. Medical Inspectorate of Factories
}

(RECEIVED FOR PUBLICATION JUNE 5, 1962)

The clinical, radiographic, pathological, and environmental features of a case of extensive aluminium fibrosis of the lungs are reported in a man of 49 years of age who had worked for $13 \frac{1}{2}$ years in the ball-mill room of an aluminium powder factory.

It is noteworthy that his symptoms were referable to the central nervous system, and that he died from terminal broncho-pneumonia following a rapidly progressive encephalopathy, associated with epileptiform attacks. He had no presenting pulmonary symptoms, and $x$-ray examination of the chest showed only slight abnormalities. Radiographic examination of the chests of 53 other workers in the same factory, and clinical examination with lung function tests of 23 of them revealed no other definite cases of aluminium fibrosis of the lung, nor any other cases with neurological signs and symptoms.

Estimations of the aluminium contents of the body tissues such as the lungs, brain, liver, and bone are also recorded. When compared with normal values, it was found that the lungs and brain contained about 20 times and the liver 122 times more than normal. As a contribution to the study of the aluminium content of normal tissues, and as a control series for the results given by Tipton, Cook, Steiner, Foland, McDaniel, and Fentress (1957), and Tipton, Cook, Foland, Rittner, Hardwick, and McDaniel $(1958,1959)$, the aluminium content of eight "normal" brains was estimated and in all cases it was found to be less than $0.6 \mu \mathrm{g}$. Al/g. wet weight.

The results of a survey of the dust concentrations in the factory are also given.

The use of aluminium compounds in the experimental production of epilepsy in primates is reviewed, and it is suggested that the neurological signs and symptoms with epileptiform convulsions which occurred in this case might have been related to aluminium intoxication. We hold the view, however, that the interstitial and nodular fibrosis found in the lungs was undoubtedly associated with the inhalation and retention of aluminium dust.

The question as to whether the dust of aluminium can damage the lungs is controversial and mysterious. On the one hand, aluminium is thought by some workers to be harmless, and is used in Canada as an antidote to the action of free silica. The practice is supported by a good deal of experimental evidence (Denny, Robson, and Irwin, 1937, 1939; Schepers, 1958) as well as by surveys in an aluminium stamping factory (Crombie, Blaisdell, and MacPherson, 1944). On the other hand, the clinical, radiographic, and pathological evidence from Germany (Doese, 1938; Goralewski, 1939, 1940, 1941, 1947, 1950;
Koelsch, 1942) and from Sweden (Ahlmark, Bruce, and Nyström, 1960; Swensson, Nordenfelt, Forssman, Lundgren, and Öhman, 1962) leaves hardly any doubt that under certain conditions, the dust of aluminium can cause severe and sometimes fatal fibrosis of the lungs.

In this country, Hunter, Milton, Perry, and Thompson (1944), found no evidence of disease in the lungs of men engaged in grinding duralumin (an alloy consisting of $95 \%$ aluminium, $4.5 \%$ copper, and traces of other metals). It should be mentioned, however, that in seven of their cases, abnormal 
$x$-ray shadows were found in the peripheral lung fields, which were not related to symptoms. Further, the fine dust to which these workers were exposed, appeared to consist mainly of alundum abrasive dust (calcined aluminium oxide). Jordan (1961) described a case of severe fibrosis of the lungs in a young woman who had been employed in a fireworks factory in the handling of a mixture containing aluminium powder and potassium perchlorate. Mitchell, Manning, Molyneux, and Lane (1961) reported the presence of fibrosis in the lungs of six out of 27 workers (with two fatal cases) who had been exposed to finely-divided aluminium dust. They also summarized most of the previous work on the subject and showed the conflicting evidence about the harmfulness or otherwise of aluminium dust when taken into the lungs. These authors also mention the work of Shaver of Canada on the effects of the inhalation of the fumes arising during the calcination of bauxite, but this is not strictly comparable, because the men engaged in this process are also exposed to the fume of amorphous silica, in addition to that of aluminium oxide.

In this paper, we report another case of pulmonary fibrosis in a worker who had been exposed to the dust of aluminium powder, and in addition, the results of clinical, radiographic, and pulmonary function tests of other workers in the same factory, and also the results of an environmental survey. It could be said that the case about to be described adds further to the confusion about the effects of aluminium powder, because though the patient had undoubted fibrosis of the lungs, his presenting symptoms were neurological, and during the course of his illness he had no overt symptoms relating to the respiratory system.

\section{Case Report}

F.L.M., aged 49 years, had worked for 17 years as a baker's roundsman, before being employed for $13 \frac{1}{2}$ years as a ball-mill operator in an aluminium flake powder factory. His illness began in October 1959, when he was found leaning against a wall in the workroom in a dazed and unresponsive state, and was sent home by the management. From this time his wife reported that he became forgetful and developed difficulty with speech. In conversation he would get so far, then stop, and could not get the words out. He began to have attacks of clonic jerking of the left leg, and later of the left arm also. These attacks would last for about four minutes, and during them, although conscious, he was quite unable to speak at all. The attacks increased in frequency up to three to four times a day. In spite of these symptoms he kept at work and was able to carry on his job without much difficulty till February 1960.

He was first seen at Hillingdon Hospital in December 1959, when he had a mild dysarthria and weakness of left arm and leg. An E.E.G. showed a generalized

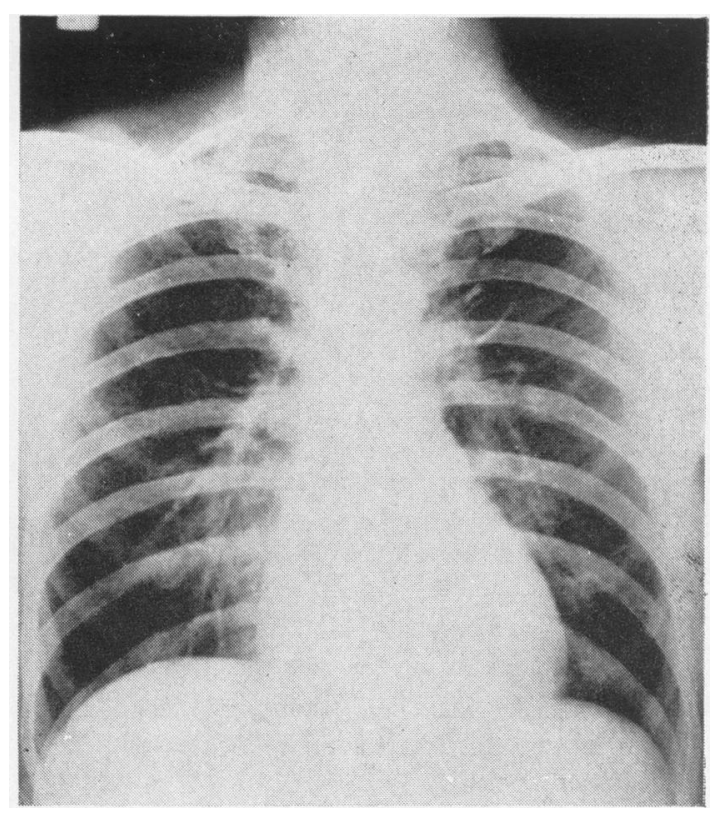

FIG. 1.-Chest radiograph showing reticular shadows in the upper two-thirds of the lung fields, with some haziness at both apices.

abnormality with frequent sustained outbursts of high voltage 2 to $3 \mathrm{c} / \mathrm{s}$ activity, having a generalized and symmetrical distribution. This was reported as suggesting some deep mid-line disturbance rather than a focal lesion in either hemisphere. When seen again in February 1960 the dysarthria and left hemiparesis had increased. A provisional diagnosis of cerebral tumour was made and he was referred to one of us (R.J.P.) at Central Middlesex Hospital where he was admitted on March 2, 1960. It is important to note that at the time of his admission to hospital he did not complain of symptoms referable to the respiratory system, and that he had at no time complained of breathlessness. Nothing relevant was discovered in his past history or in his family history.

On examination, he had no cyanosis, clubbing of the fingers, or oedema. Blood pressure was $130 / 80 \mathrm{~mm}$. $\mathrm{Hg}$. The trachea was central, the chest moved well, breath sounds were normal, and there were no adventitious sounds. A radiograph of the chest (Fig. 1) was at first passed as normal, but on closer examination revealed increased linear and reticular shadows, extending out to the peripheral lung fields with some diffuse shadowing in both upper zones, extending to the apices. The right diaphragm was slightly elevated.

As regards the neurological picture: he was a righthanded man; he was very slow in all his reactions, and did not seem unduly distressed by his disability. His speech was slurred and he had a mild nominal dysphasia. There appeared to be some deterioration of memory for recent events, but he was normally orientated and there was no evidence of hallucinations or delusions. The fundi were normal and visual fields full. He had a mild spastic left hemiparesis involving face, arm, and leg with 
increased tendon reflexes in the left arm and leg, and at first an equivocal left plantar response. Later both plantar responses became frankly extensor. There was no objective sensory loss.

During the next two months, while he was in the Central Middlesex Hospital, he had an increasing number of focal convulsive attacks which at first started with twitching of the left arm and leg and were associated with complete aphasia. Later, the fits originated on the right side of the body and developed into generalized convulsions, followed by deep coma.

On April 14 he developed a small right pulmonary embolus. There was gradual mental deterioration during his stay in hospital and on May 7, 1960, he was transferred to Hillingdon Hospital where he became progressively more confused and died on July 19, 1960, after the onset of broncho-pneumonia.

\section{Investigations}

\section{January 1960}

E.E.G. REPORT.-This is an unusual record. The dominant rhythm is about $8 \mathrm{c} / \mathrm{s}$ and has greatest amplitude in the central and frontal areas, where it blocks on opening the eyes. In the post-central areas, the amplitude is lower, and the frequency about $9 \mathrm{c} / \mathrm{s}$.

From this background activity fairly frequent sustained outbursts of high voltage 2 to $3 \mathrm{c} / \mathrm{s}$ activity arise with generalized and symmetrical distribution, but with greatest amplitude in the frontal regions.

Later during the recording the patient became drowsy, and sleep changes and arousal responses are recorded, but without significant asymmetry.

The character of this record suggests some deep and mid-line disturbance rather than a localized lesion in either hemisphere.

\section{March 1960}

HAEMOGLOBIN.-69\% with some hypochromia, anisocytosis, and polychromasia of the red cells.

E.S.R. (Westergren). $-23 \mathrm{~mm}$. in one hour.

Blood urea, plasma proteins, liver function tests, and examinations of the urine were normal.

Cerebrospinal Fluid.-Pressure normal with a free rise and fall; 17 R.B.C. per c.mm., protein $10 \mathrm{mg}$./ $100 \mathrm{ml}$.; sugar $70 \mathrm{mg} . / 100 \mathrm{ml}$.; W.R. negative; Lange normal.

Air ENCEPHAlogram.-The left lateral ventricle was a little larger than the right; there was no displacement, the appearances being consistent with a minor degree of left cerebral atrophy.

Carotid Angiograms.-Normal.

\section{April 1960}

E.E.G.-The E.E.G. has changed in character. The alpha-rhythm is of lower voltage and less well maintained, and no longer most prominent in the pre-central areas as previously, and there is a mild and diffuse dysrhythmic overlay.

Furthermore the high voltage paroxysmal slow activity has reduced considerably, and is not in fact seen at all till the conclusion of the record, when some "sharp" outbursts occur. They may be related to his degree of relaxation. There is no significant asymmetry, and the general character does not suggest a localized lesion in either hemisphere.

\section{Pathology}

Post-mortem examination carried out two days after death, showed a poorly nourished adult man. The cerebral vessels were healthy and there was no meningeal thickening. The brain was oedematous. The lateral ventricles were a little dilated, but no localized lesion was found in the brain. The spinal cord on naked eye examination was normal. The right side of the heart was widely dilated, but not hypertrophied, and the left ventricle was rather small. The myocardium appeared to be healthy and there was no valvular disease. Early atheromatous changes were seen in the coronary arteries and aorta.

Both pleural cavities showed scattered adhesions, and the lungs were bulky. There was diffuse fibrosis in the upper lobes of both lungs, and some hard nodules in both upper lobes could be palpated. On section, the upper lobes showed interstitial emphysema. The upper pole of the right lower lobe also showed fibrosis on naked eye examination, and there was a little terminal consolidation in both lower lobes. Apart from some colloidal enlargement of the thyroid gland, the other organs were normal.

Sections for microscopy were taken from all parts of the lung, and confirmed the presence of aluminium dust and fibrosis in all the sections examined. There was much more fibrosis in the upper than in the lower lobes, but none the less, the general picture was the same in all sections. As stained by haematoxylin and eosin, the sections showed two forms of fibrosis: (1) localized whorls of fibrous tissue, often associated with considerable deposits of pigment (Fig. 2); and (2) more diffuse fibrosis in the alveolar walls (Fig. 3). The histological picture was similar to that described by Mitchell et al. (1961), and histological sections were exchanged with these authors. Under refracted light aluminium flakes about $20 \mu$ across could be seen in the lungs, and these were similar in size and shape to the aluminium dust collected in the factory (see Figs. 4 and 5). They were also similar to the material seen and illustrated by Goralewski (1950). Sections stained by Van Gieson's method confirmed the amount of fibrosis present, and stains with "Aluminon" (an ammonium salt of aurinetricarboxylic acid) gave positive results, indicative of the presence of aluminium. With this particular stain, there appeared to be more aluminium dust in the upper lobes than in the middle or lower lobes. Sections of brain tissue stained with aluminon also gave positive results, indicating the presence of aluminium in the brain. No aluminium particles, however, were seen in the brain tissue.

Histological examination of the brain showed no evidence of abnormality and in particular, none of syphilis, vascular disease, intracranial tumour, or inflammation, and there was nothing seen to support a diagnosis of Pick's disease or Alzheimer's disease. 


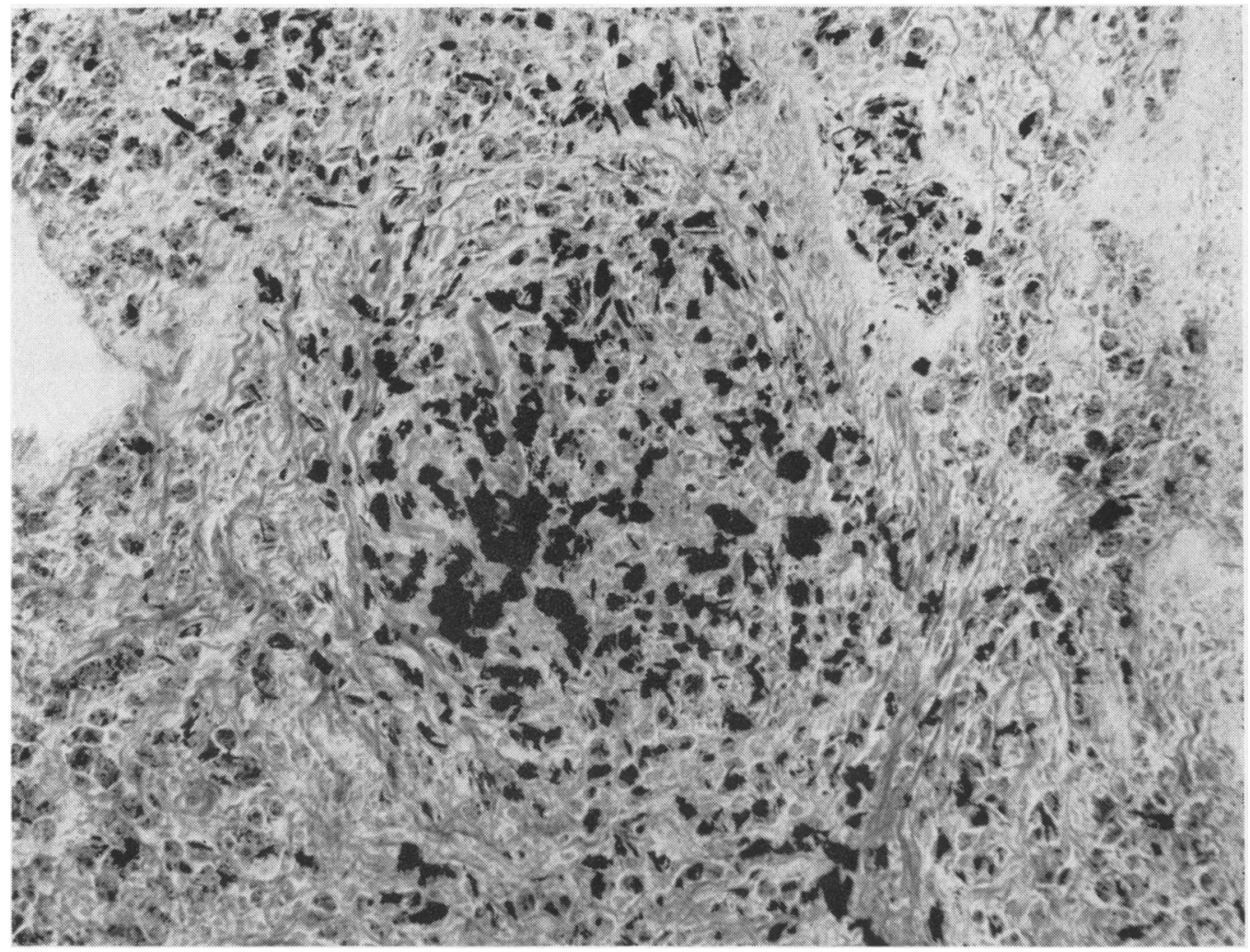

FIG. 2.-Photomicrograph of histological section of lung, showing aluminium particles surrounded by concentric fibrous tissue. (Van Gieson. $\times$ 180.)

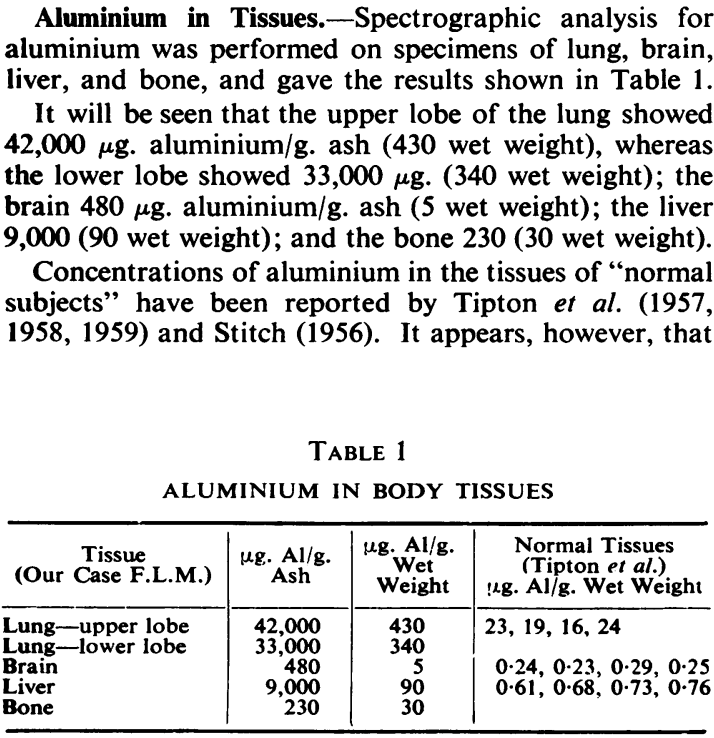

the values for aluminium for normal tissue given by Stitch, and also in some earlier work by Tipton, were not reliable, and comparison is best made with the four later reports by Tipton and his colleagues. The average values, expressed as $\mu \mathrm{g}$. $\mathrm{Al} / \mathrm{g}$. wet weight are also given in Table 1. In our case the aluminium content of the lungs was 18 times higher than normal; of the brain it was 17 times the normal, and the liver 122 times.

The concentration in the brain was unexpectedly high, and in order to test the analytical technique eight brains from subjects who had not been exposed industrially to aluminium dust were analysed in the same way. In each case the aluminium content was less than $0.6 \mu \mathrm{g}$. $\mathrm{Al} / \mathrm{g}$. wet weight, which was the limit of detection by the technique used.

Concentrations of aluminium in lung tissue from two cases of pulmonary fibrosis associated with aluminium dust were given by Mitchell et al. (1961) as parts per million of aluminium in wet tissue as follows: (i) 227 (root), 15 (apex), and trace (base); (ii) 12 (root), 15 (apex), and 8.5 (base). These figures are clearly, with one exception, not of the same order of magnitude, as those given for our case. (Parts per million is another way of expressing $\mu$ g. per g.) 
Environmental Survey

Granules of aluminium prepared from scrap aluminium foil are ball-milled with $1 \frac{1}{2}$ to $5 \%$ stearic acid in a burnt town gas atmosphere to produce aluminium powder. The process is continuous, the fine powder being fed into an aluminium powder receiver and fresh materials being fed into the ballmill by screw feed from a hopper. Several such ball-mills are operating in one large workshop. The environment in this workshop was not unduly dusty, the only causes of atmospheric dust being the hourly removal and replacement of the aluminium powder receivers, floor cleaning, and the occasional release of excess pressure in the ball-mills. Eight 12-hour samples at each of two positions in this workroom gave average dust concentrations as follows:

1. Total dust: $0.94 \mathrm{mg} . / \mathrm{m}^{3}$ (range 0.42 to $\left.1.93 \mathrm{mg} . / \mathrm{m}^{3}\right)$. $71 \%$ aluminium.

"Respirable": $0.24 \mathrm{mg} . / \mathrm{m}^{3}$ (range 0.12 to 0.37 $\left.\mathrm{mg} . / \mathrm{m}^{3}{ }^{3}\right) . \quad 48 \%$ aluminium.

2. Total dust: $1.46 \mathrm{mg} . / \mathrm{m}^{3}$ (range 0.75 to $\left.3.62 \mathrm{mg} . / \mathrm{m} .{ }^{3}\right)$. $60 \%$ aluminium.
"Respirable": $0.38 \mathrm{mg} . / \mathrm{m}^{3}$ (range 0.23 to 1.11 $\left.\mathrm{mg} . / \mathrm{m}^{3}\right) . \quad 42 \%$ aluminium.

The "respirable" samples were taken through a horizontal elutriator as described by Wright (1954).

Although the workmen received exposures to greater concentrations than those given above during the changing of the powder receivers the times of exposures were very short, measured in seconds rather than minutes. The aluminium receivers from the ball-mills are taken to a small room adjacent to the main workshop, and their contents emptied into large steel drums. These in turn are moved to a second small room, adjusted to weight by hand, vibrated to give even packing, and sealed for transit. These two operations are very dusty. Two samples in the packing room during weighing and vibrating gave total dust concentrations of $10 \mathrm{mg} . / \mathrm{m}^{3}$ and $32 \mathrm{mg} . / \mathrm{m}^{3}$ ( $\left.72 \% \mathrm{Al}\right)$ and "respirable" dust concentrations of $1.4 \mathrm{mg} . / \mathrm{m}^{3}$ and $10 \mathrm{mg} . / \mathrm{m}^{3}(40 \% \mathrm{Al})$, although the average concentration for four sampling periods each of 12 hours' duration in the same position gave $1.75 \mathrm{mg} . / \mathrm{m}^{3}$ (range 0.76 to $3.54 \mathrm{mg} . / \mathrm{m} .^{3}$ ),

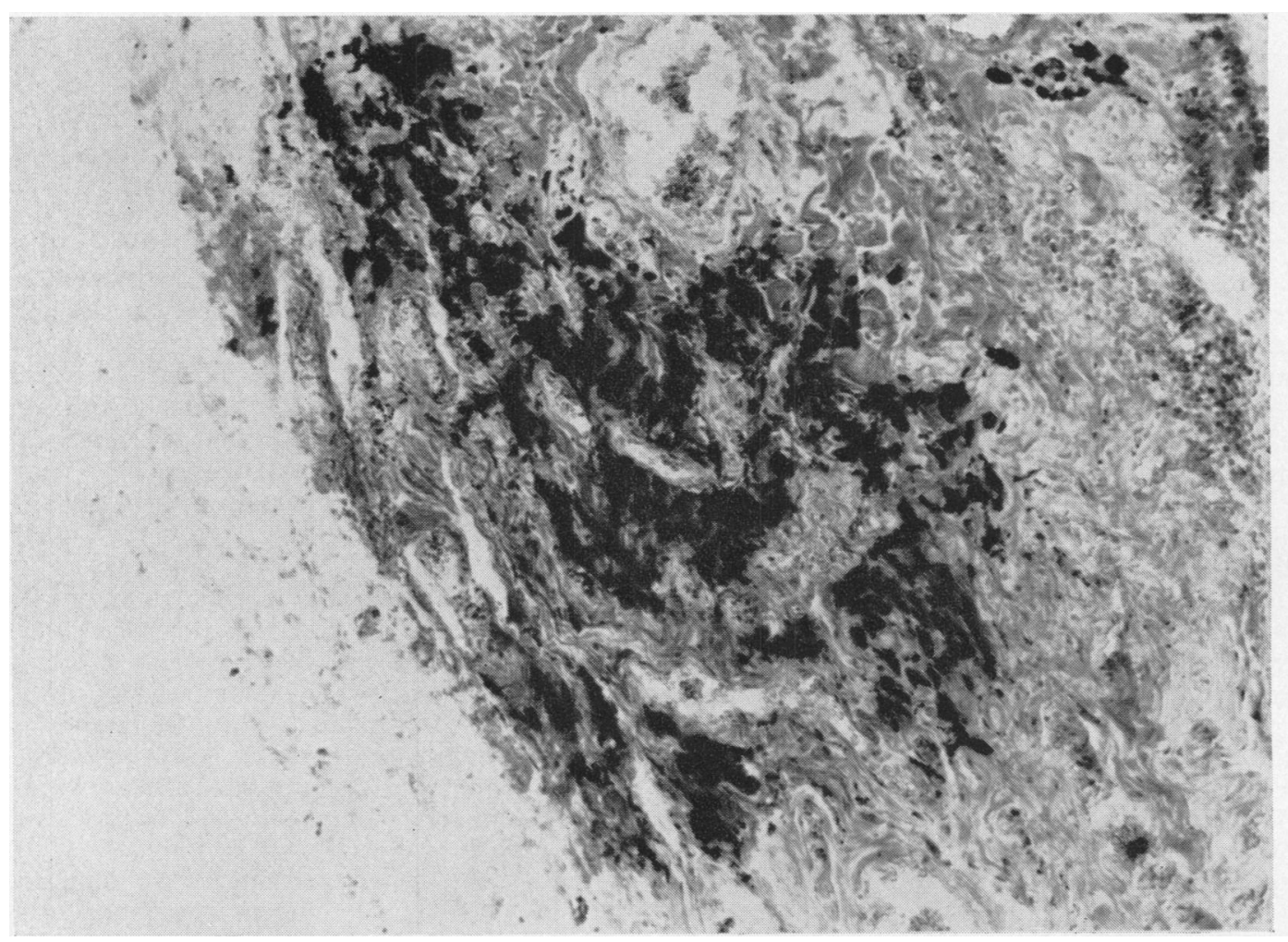

FIG. 3.-Photomicrograph of histological section of lung, showing diffuse linear fibrosis surrounding pigment (mostly aluminium particles) with fibrosis and thickening of alveolar walls at top right. (Haematoxylin and eosin. $\times 163$.) 


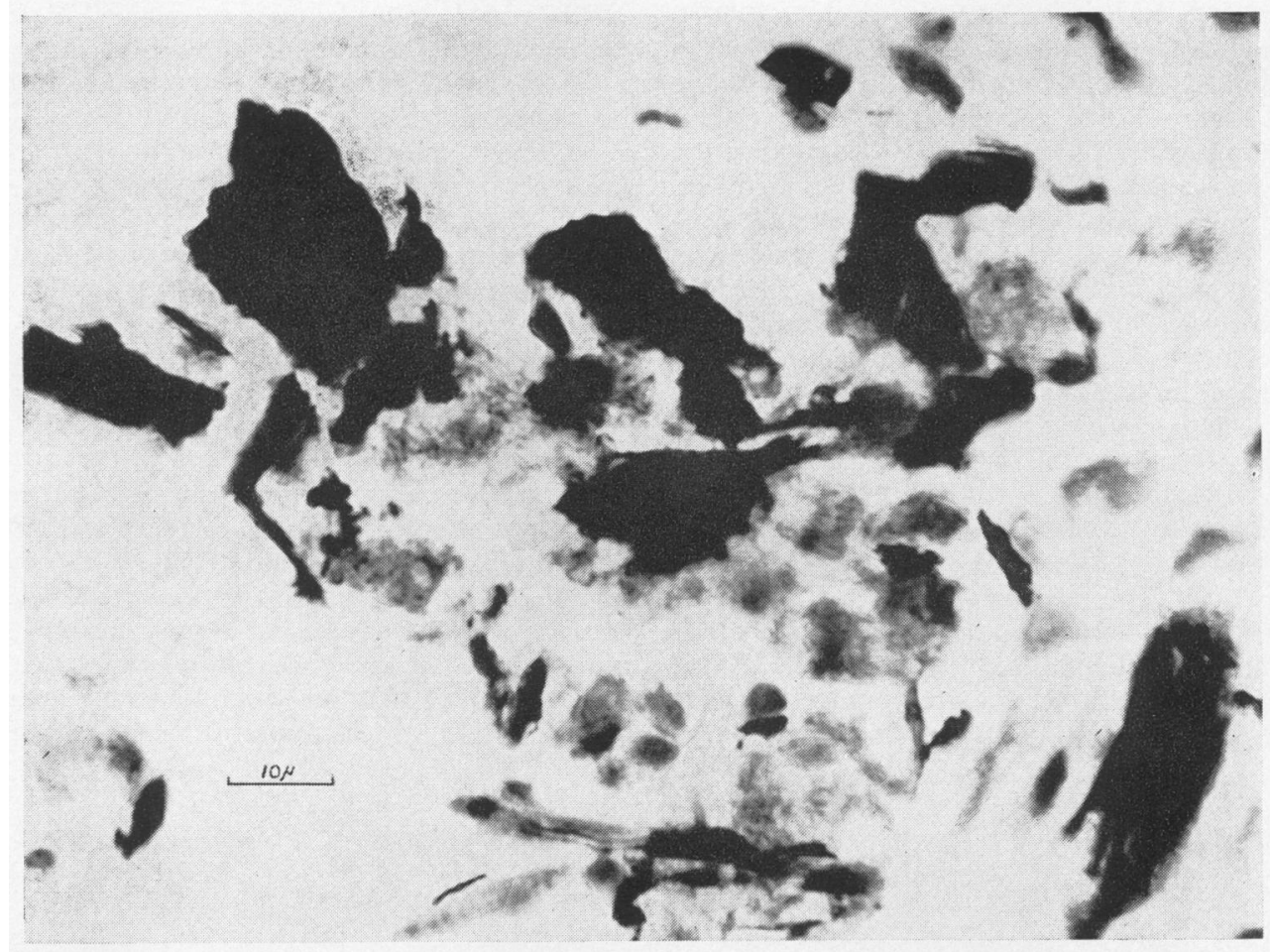

FIG. 4.-Photomicrograph of histological section of lung, showing aluminium particles up to $25 \mu$ in the lung tissues. $(\times$ 1062.) (Compare with Fig. 5.)

$57 \% \mathrm{Al}$ for total dust and $0.55 \mathrm{mg} . / \mathrm{m}^{3}$ (range 0.26 to $\left.1.23 \mathrm{mg} . / \mathrm{m}^{3}{ }^{3}\right), 27 \% \mathrm{Al}$ for "respirable" dust. Precautions against fire ohserved in this factory severely limited the scale and type of atmospheric sampling, and it was found impossible to monitor the workmen's breathing zone during these dusty operations, for which the workmen wore approved dust respirators. However, analysis of 14 filter pads of used masks showed an average collection of $33 \mathrm{mg}$. aluminium per hour of wear, the estimated time of use giving an average value of four hours per shift (range one to six hours). Extraction of the dust from the masks with methyl alcohol, and a single sedimentation in alcohol to give the "respirable" fraction, showed that about $98 \%$ of this dust was of large particle size, although some of the finer dust may have been retained in the mask.

The finished powders were silver in colour, the individual particles being present as irregularlyshaped flakes. Unlike the "pyro" powder described by Mitchell $e t$ al., no additions were made except when dyed powders were produced. The dyeing of the finished powder was carried out in a separate building, and only occasional small batches of powder were involved in an essentially wet process. No other process or materials have been used in this factory, so that there is a clear-cut exposure to aluminium dust.

Three bulk samples of the finished powder lost $1.8 \%, 0.7 \%$, and $0.3 \%$ on washing with methyl alcohol. Elutriation in alcohol gave "respirable" fractions of $3.2 \%(77 \% \mathrm{Al}), 1 \cdot 1 \%(74 \% \mathrm{Al})$, and $4.5 \%(73 \% \mathrm{Al})$, the aluminium content of the non"respirable" fraction being $79 \%, 84 \%$, and $80 \%$ respectively.

Surface oxidation of the aluminium powder is accepted in the industry to the extent that each $9 \mathrm{lb}$. of powder produced by the mill is replaced by only $8 \mathrm{lb}$. of aluminium. Qualitative spectrographic analysis of 25 samples of the "respirable" dust showed trace quantities of $\mathrm{Ti}, \mathrm{Ni}, \mathrm{Cu}, \mathrm{Fe}, \mathrm{Pb}, \mathrm{Sn}$, $\mathrm{Ca}, \mathrm{Si}, \mathrm{Mg}, \mathrm{Mn}, \mathrm{Zn}$, and $\mathrm{Ba}$ such as would be expected in scrap aluminium foil. Beryllium was not detected.

Fig. 6 shows the percentage (by number) of aluminium flakes of different size ranges passing through an elutriator such as was used in the atmospheric sampling. These data were obtained from thermal precipitator samples taken at both ends 


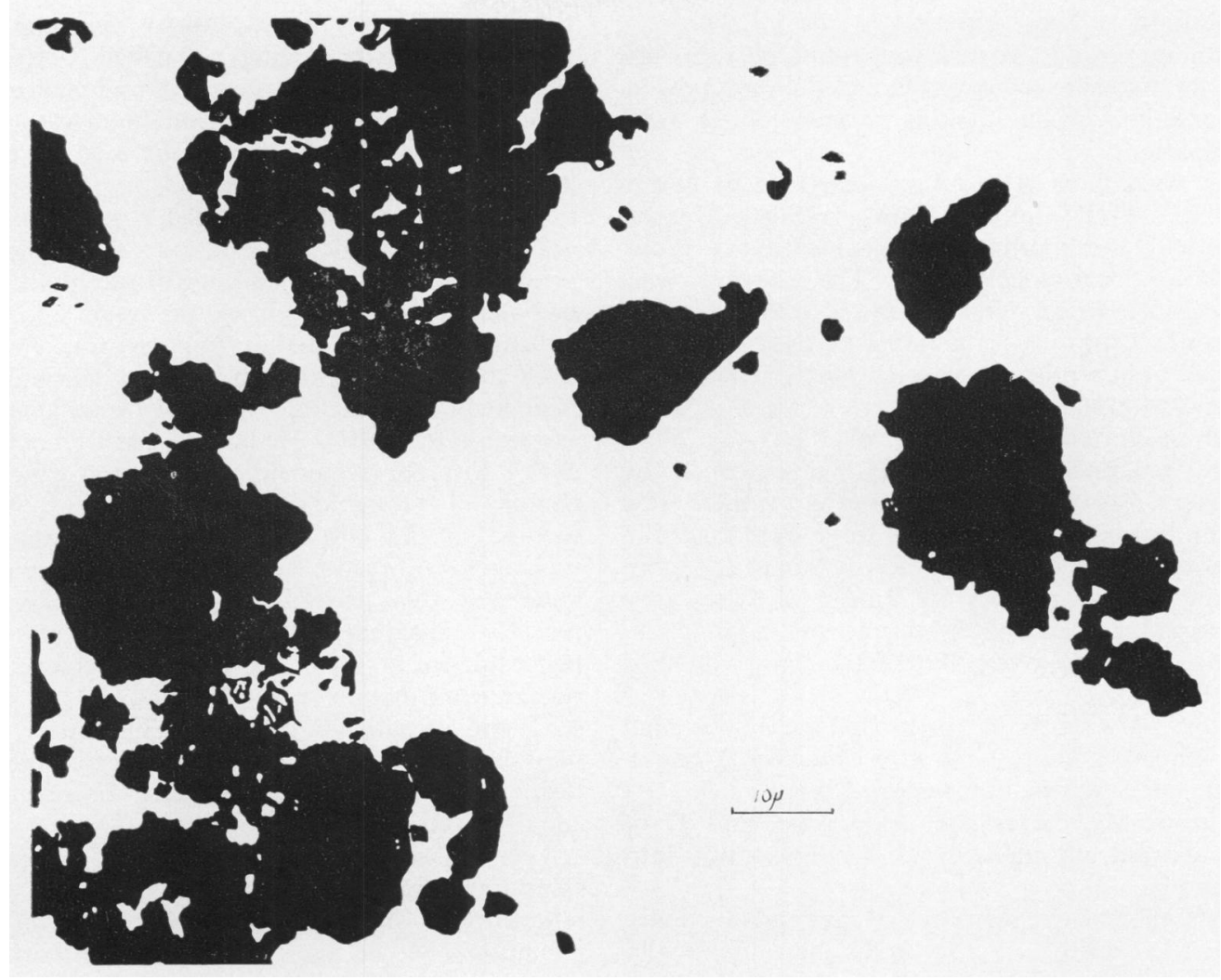

Fig. 5.-Konimeter sample of aluminium dust from factory atmosphere. Particle sizes similar to those found in the lungs. $(\times$ 1000.) (Compare with Fig. 4.)

of an elutriator of $11,000 \mathrm{~cm} .^{2}$ sampling a cloud of aluminium dust at $\mathbf{1 0 0}$ litres per minute. It can be seen that "respirable" dust, i.e. that which passed the elutriator, contained a high percentage of the large flakes from the original dust, with a cut-off of 25 to $35 \mu$ diameter as against a theoretical cut-off of $4.26 \mu$ diameter for aluminium spheres.

Examination of Other Workers in the Factory.Fifty-four people were employed in the factory, and of these 18 worked in the mill room, where there was maximal exposure to the dust of aluminium. Of the 54 employees $48(89 \%)$ volunteered for radiological examination and these included 13 of the 18 millroom workers $(72 \%)$, who also attended for clinical examination. Ten other people also came for clinical examination, making a total of 23 , or $43 \%$ of the total factory population.

$X$-ray Examinations. - Forty-eight people attended for $x$-ray examination and these included office workers, laboratory staff, and aluminium foil tearers, none of whom was employed on a dusty job,

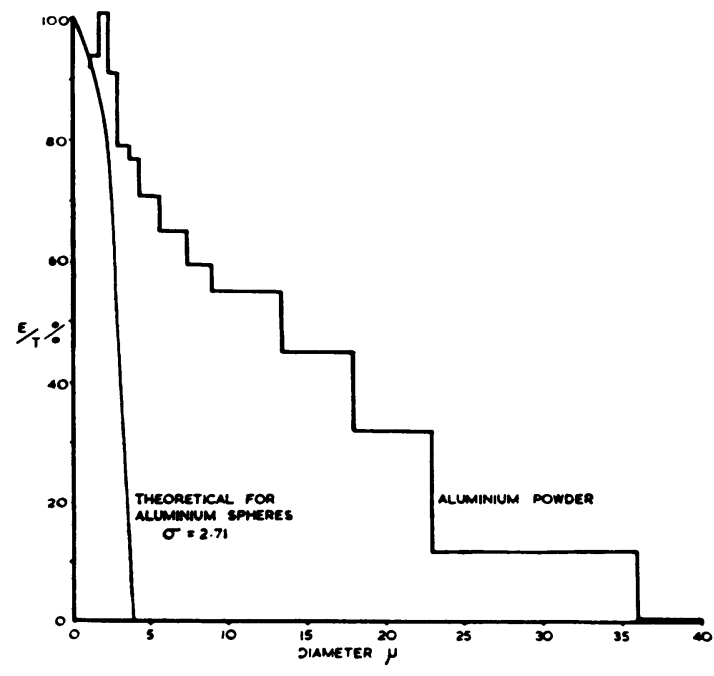

Fig. 6.-Percentages of size ranges of aluminium flakes passing through a horizontal elutriator, compared with the theoretical curve for aluminium spheres (see text). 
in addition to those exposed to the inhalation of aluminium powder. In addition, five employees came from an associate factory where aluminium powder is made into paste, making a total of $53 x$-ray examinations

The $x$-ray films of the chest were read by two of us (A.I.G. McL. and G.K.) and classified in accordance with the international classification of radiographs of pneumoconioses. The subjects were divided into three main groups: (I) those with a maximum exposure to aluminium dust; (II) with minimal or intermittent exposure; and (III) those not exposed to aluminium dust.

The results of the reading of the $x$-ray films, without reference to age or length of exposure, are as follows. Of the 13 workers in group I, there were six with normal $x$-ray films $(0)$, three were placed in Category $\mathrm{L}$, two in Category $\mathrm{Lm} 1$, one in Category $\mathrm{m} 1$, and one in Category $\mathrm{m} 2$. In two of these cases, we noted that the $x$-ray appearances were similar to those seen in the $x$-ray film of the man who died (Fig. 1).

Of the 12 workers in group II, nine had normal $x$-ray films (0), one was put into Category $Z$, one in Category L, and one in Category Lm1.

In group III, there were 28 workers, and 27 of them showed normal films. One was put into Category $\mathbf{L}$.

It is seen that the incidence of $x$-ray abnormality is higher in the 13 workers who had been maximally exposed to aluminium dust, lower in those intermittently exposed, and very much lower in those who had not been exposed. The abnormalities found were of a minor type, and indeed were much less severe than would be expected in a group of men who had been exposed over varying periods of years to fairly high concentrations of aluminium dust.

Clinical and Lung Function Examinations.Twenty-three workers attended for clinical examinations, and of these 13 had worked in the aluminium powder room. A full occupational and medical history was taken, the height and weight of each subject was recorded, and a specimen of urine in each case was tested for protein and sugar.

Simple tests of respiratory function were performed by each person who attended the clinical examination. Forced inspiratory and expiratory spirograms and maximum voluntary ventilation at 70 respirations per minute were recorded on a light-weight spirometer (D'Silva and Kazantzis, 1954; Bernstein, D'Silva, and Mendel, 1952). The forced vital capacity, the one-second forced expiratory volume expressed as a percentage of the vital capacity (F.E.V..$_{1.0} \%$ ), the mid-expiratory flow rate, and the time constant of the expiratory spirogram were calculated from the tracings. The mean performance after three trials was recorded and expressed at BTPS. Under the conditions obtaining at the survey it was not possible to carry out tests of alveolar diffusion of gases. The results of the respiratory function tests are shown in Table 2, where figures outside two standard deviations from the mean results in an age-matched control group are shown in bold. The control group was made up of other industrial workers, mainly foundrymen.

Of the 23 workers examined, one (Case 3) complained of a moderate degree of breathlessness on exertion (Grade III). He had, in addition, a chronic cough with some mucoid sputum, and gave a past history of bronchitis and pneumonia. He had worked in the mill room exposed to aluminium powder for 13 years, but his respiratory symptoms antedated this period and had not deteriorated recently. His chest radiograph was normal, but he had evidence of increased airway resistance on the respiratory function tests $\left(F . E . V ._{1.0} 62 \%\right.$; T C. 1.05 sec.), and a small vital capacity. This clinical picture may have resulted from exposure to aluminium dust, but a diagnosis of chronic bronchitis was equally likely.

Two other men complained of respiratory symptoms. Case 4 had chronic cough and sputum but without shortness of breath. He had had pneumonia at the age of 16 . He had worked for 40 years in a rubber factory where he was exposed to a variety of dusts, in particular that of talc. He had been exposed to aluminium powder in the mill room for the past five years. The respiratory function tests showed evidence of increased airway resistance (F.E.V.1.0 $61 \%$; T.C. $1 \cdot 10$ sec.). The chest radiograph showed opacities at both apices. Owing to the previous long exposure to talc, it was not possible to attribute the findings to exposure to aluminium powder.

The only other worker with respiratory symptoms (Case 5) complained of chronic cough with mucopurulent sputum, worse in the winter. He had, in addition, wheezing and a tight feeling in the chest, not related to dust exposure. He gave a past history of bronchitis, and although he had worked in the mill room and was exposed to aluminium powder for 22 years, he was under the impression that some of his symptoms had antedated this employment. Examination revealed the presence of rhonchi in both lungs, but respiratory function tests gave results within the limits of normal. The chest radiograph showed a few nodular opacities over both lung fields (Category $\mathrm{ml}$ ). A diagnosis of chronic bronchitis was made.

The remaining workers did not have symptoms 


\begin{tabular}{|c|c|c|c|}
\hline$=\circ$ 。旁 & 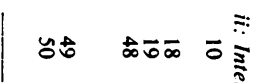 & 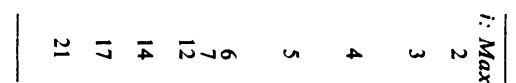 & zog \\
\hline & 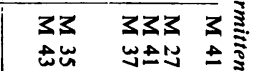 & 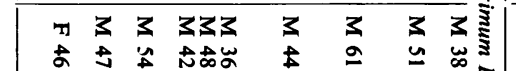 & 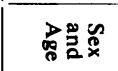 \\
\hline 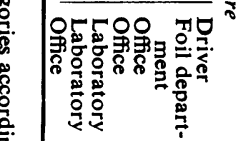 & 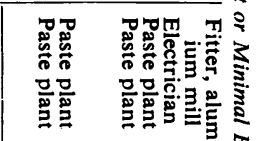 & 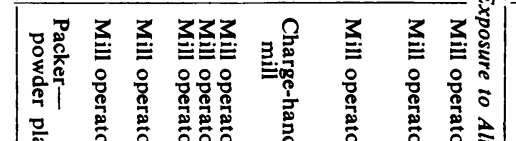 & 亏a \\
\hline 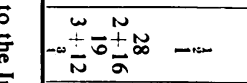 & 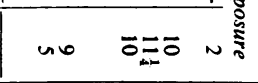 & 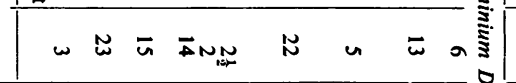 & 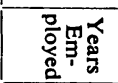 \\
\hline 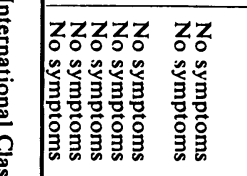 & 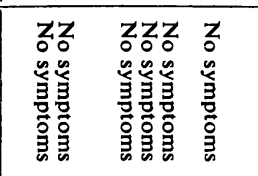 & 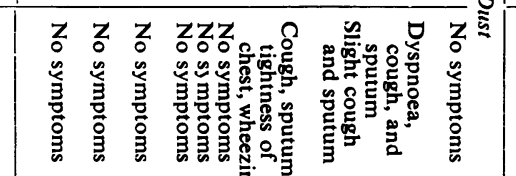 & 譬 \\
\hline 0000000 & 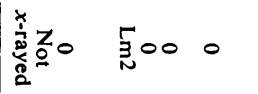 & 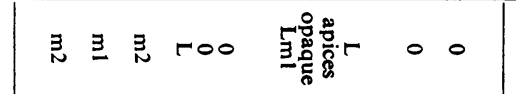 & 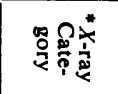 \\
\hline 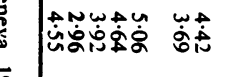 & 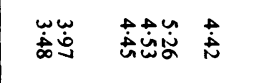 & 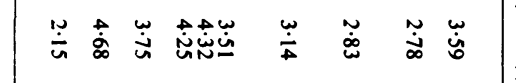 & 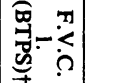 \\
\hline 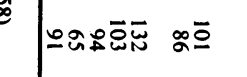 & 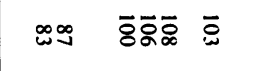 & 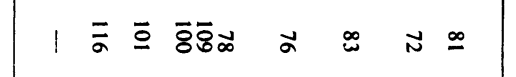 & 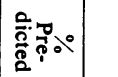 \\
\hline 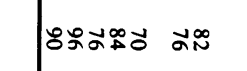 & 20 & 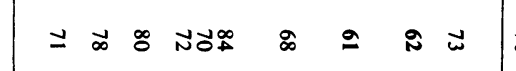 & 西 \\
\hline 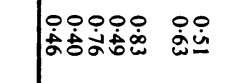 & 象 & 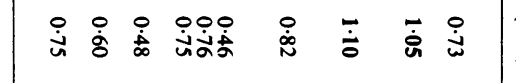 & 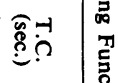 \\
\hline 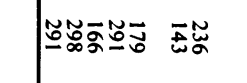 & 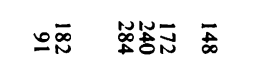 & 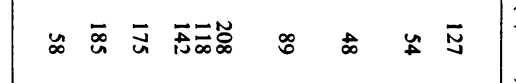 & 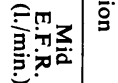 \\
\hline 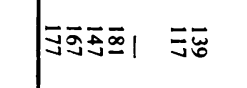 & 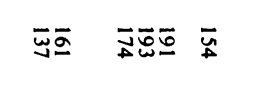 & 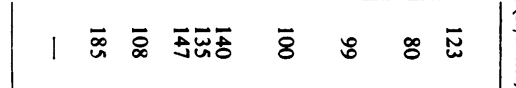 & 嚄 \\
\hline 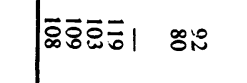 & 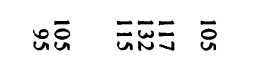 & 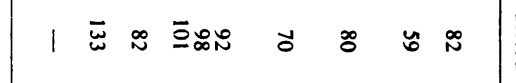 & 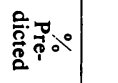 \\
\hline 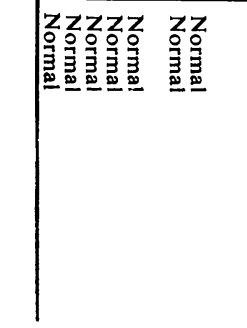 & 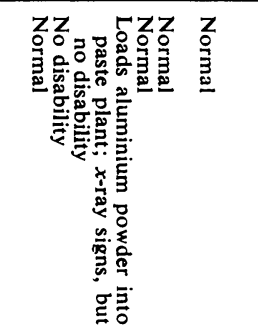 & 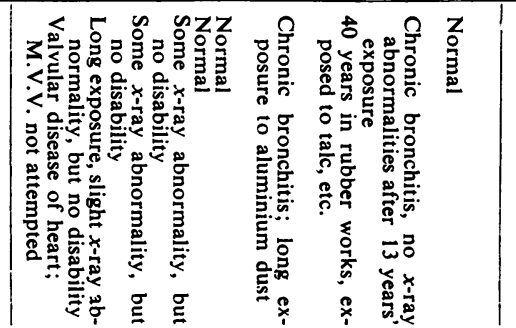 & 尊 \\
\hline
\end{tabular}


referable to the respiratory system, neither did they show evidence of significant abnormality on the respiratory function tests. Two of these men (Case 14 and Case 17) had worked continuously on the ballmills for 15 and 23 years respectively. It will be seen, therefore, that no other definite cases of aluminium fibrosis of the lung were found in this series.

\section{Discussion}

Although there are no reports in the literature of a neurological disorder attributable to aluminium intoxication in man, it has been known for some years that hydrous oxides of aluminium applied to the surface of the brain in monkeys and apes will produce severe recurrent epilepsy (Kopeloff, Chusid, and Kopeloff, 1954). Aluminium oxide powder, hydrous oxides of aluminium, aluminium cream, and alums have been found to have such epileptogenic properties. The materials have been applied to the surface of the brain, injected into the cerebral cortex, and injected into the cisterna magna with positive results. Reactions have always followed a latent period normally of several weeks. Typical attacks began with clonic seizures of a limb or with focal seizures progressing by Jacksonian spread to involve the musculature of the entire body. Epileptic attacks have developed spontaneously or followed stress on a variety of stimuli. It was found to be characteristic of aluminium-induced seizures that, once developed, the epileptic response generally persisted over a period of years. While many materials applied to the surface of the brain in this way may produce focal epilepsy, no other group of compounds is known which will produce recurrent focal attacks for a number of years following on a latent period after application.

Our case presented the picture of a rapidly progressive encephalopathy and cerebral degeneration, starting with focal clonic seizures in the left leg, and aphasia, later increasingly frequent, and severe motor Jacksonian attacks, generalized convulsions, and progressive dementia. The aetiology is obscure. Histological examination of the brain revealed no evidence of cerebrovascular disease, intracranial tumour, inflammatory disease, or syphilis, and there was no histological evidence to support a diagnosis of Pick's or Alzheimer's disease. There was no past history of head injury or epilepsy and no evidence that he may have suffered from a deficiency disease or chronic intoxication by alcohol or drugs. It seems possible that the encephalopathy was due to aluminium intoxication. This suggestion is based on the high aluminium content of the brain, the experimental effects of the application of aluminium compounds to the central nervous system in primates, and the absence of any other known cause for his illness.

There seems to be little doubt that the interstitial fibrosis found in the lungs of our case was associated with the inhalation and retention of aluminium particles, and that the histological appearances are similar to those described by Goralewski (1950) and by Mitchell et al. It is all the more surprising, therefore, that the extensive fibrosis found did not produce more abnormal $x$-ray shadows and symptoms of pulmonary disability. Admittedly, the presenting symptoms which were neurological in type might have masked any symptoms referable to the respiratory system. In any case the $x$-ray picture was not similar to that described by Mitchell et al., though the fibrosis was as extensive as that found in their cases, and the aluminium content of the lungs was much higher. The two cases reported by them were last exposed to aluminium dust nine months and 15 months respectively before death, whereas in our case the interval between the last exposure and death was six months; further, he had been exposed to lower concentrations of dust. Nagelschmidt (1960) suggests that interstitial fibrosis of the lungs is commonly caused by soluble dusts, and comments on the disproportion between the amount of dust and the amount of fibrosis in berylliosis and aluminosis. In our case there was no disproportion between the amounts of dust and the fibrosis. The dust associated with the cases of Mitchell et al. was, at one time, coated with a mixture of mineral oil and stearic acid, and it is possible that the mineral oil or some other factor gave an increase in solubility resulting in a rapidly progressive fibrosis and low residual aluminium. The aluminium dust in our case was coated with stearic acid which is believed to lessen the solubility of aluminium. The large quantity of dust present in the lungs and the microscopical appearance of the individual particles do not suggest that it is easily soluble. In this case, therefore, there is interstitial fibrosis associated with a comparatively insoluble dust. The aluminium in the brain and other tissues could have come partly from the lungs and partly from the gastro-intestinal tract.

We are indebted to Dr. T. O. Garland for drawing our attention to the case; to Dr. C. C. Evans for the reports on the E.E.G's; to Dr. F. G. Greenwood for the $x$-ray film (Fig. 1); to the Government Chemist for the analyses of aluminium in the tissues; to $\mathrm{Mr}$. $\mathrm{R}$. Drew for help with the chemical analyses; to Mr. Brian Biles for much assistance, including the preparation of the illustrations; to Miss Pamela Rogers for secretarial assistance; to Mr. P. Casbolt, Mr. G. Gibbs, and Mr. $D$. Fine for help in the environmental investigation; and to the management and workers of the factory concerned for their co-operation in the investigation. 


\section{REFERENCES}

Ahlmark, A., Bruce, T., and Nyström, А. (1960). Silicosis and other Pneumoconioses in Sweden. Svenska Bokförlaget, Stockholm. Bernstein, L., D'Silva, J. L., and Mendel, D. (1952). Thorax, 7, 255. Crombie, D. W., Blaisdell, J. L., and MacPherson, G. (1944). Canad. med. Ass. J., $50,318$.

Denny, J. J., Robson, W. D., and Irwin, D. A. (1937). ibid., 37, 1. Dי, (1939). ibid., 40, 213.

D'Silva, J. L., and Kazantzis, G. (1954). Thorax, 9, 128.

Doese, M. (1938). Arch. Gewerbepath. Gewerbehvg., 8, 501 Goralewski, G. (1939), ibid., 9, 676.

(1940). ibid., 10, 384

(1941). ibid., 11, 106.

(1947). Z. ges. inn. Med., 2, 665. (1950). Die

(Arbeitsmedizin No. 26.) Barth,

Hunter, D., Milton, R., Perry, K. M. A., and Thompson, D. R. (1944) Brit. J. industr. Med., 1, 159
Koelsch, F. (1942). Beitr. Klin. Tuberk, 97, 688

Kopeloff, L. M., Chusid, J. G., and Kopeloff, N. (1954). Neurology (Minneap.), 4, 218.

Mitchell, J., Manning, G. B., Molyneux, M., and Lane, R. E. (1961). Brit. J. industr. Med., 18, 10.

Nagelschmidt, G. (1960). ibid., 17, 247.

Schepers, G. W. H. (1958). Proc. 9th Conference McIntyre Res. Found., 1.

Stitch, S. R.(1956). A.E.R.E., MRC/R, 1952.

Swensson, $\AA$. Nordenfelt, O., Forssman, S., Lundgren, K. D., and Öhman, H. (1962). Int. Arrh. Gewerbepath. Gewerbehyg., 19. Ohman, H. (1962). Int. Arch. Gewerbepath. Gewerbehyg., 19,

Tipton, I. H., Cook. M. J., Foland, J. M., Rittner, J., Hardwick, M. and McDaniel, K. K. (1958). Oakridge National Laboratory Reports: Central Files No. 58-10-15.

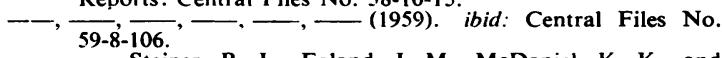
Fentress, Steiner, R. L., Foland, J. M., McDaniel, K. K., and 57-2-4 (b), 57-11-33 (c)

Wright, B. M. (1954). Brit. J. industr. Med., 11, 284. 